\title{
A singularidade dos estudantes com deficiência intelectual frente ao modelo homogeneizado da escola: reflexões sobre o processo de inclusão
}

\author{
Roseane Cunha* \\ Maristela Rossato**
}

\section{Resumo}

O presente trabalho tem por objetivo refletir sobre a singularidade dos estudantes com deficiência intelectual frente ao modelo homogeneizado da escola de conceber os processos de aprendizagem. A deficiência intelectual assume, neste cenário, um caráter restritivo, anulando a construçáo histórica das pessoas com deficiência. Teoricamente, recorremos à Teoria da Subjetividade de González Rey visando ter uma base que possibilitasse recuperar o caráter dialético e complexo da expressão do sujeito na produçáo de sentido subjetivo. Metodologicamente recorremos à Epistemologia Qualitativa que tem como base o caráter dialógico, construtivo-interpretativo e singular na produção do conhecimento. Trabalhamos com estudo de caso múltiplo, por meio da observação da prática pedagógica, análise documental e indutores orais para a expressão dos participantes. No presente artigo a discussão orienta-se pelo movimento empírico de uma professora na busca de condiçôes para promover a inclusão de estudantes das classes especiais para o ensino regular. É possível concluir que os estudantes com deficiência intelectual produzem sentidos subjetivos sobre sua aprendizagem escolar, podendo mobilizá-la ou limitá-la, a depender das produçóes simbólico-emocionais do processo.

Palavras-chave: Deficiência intelectual; Sujeito; Inclusão; Aprendizagem; Subjetividade.

* Mestranda em Educação pela Universidade de Brasília, Brasília, Distrito Federal, Brasil.

** Professora doutora da Universidade de Brasília, Brasília, Distrito Federal, Brasil. 


\title{
The uniqueness of students with intellectual disabilities in the homogenized school model: reflections on the process of inclusion
}

\begin{abstract}
This paper aims to reflect on the uniqueness of students with intellectual disabilities in opposition to the homogenized school model to conceive learning processes. The intellectual disability assumes, in this scenario, a restrictive character, annulling the historical construction of disabled people. Theoretically, we turn to González Rey Subjectivity Theory in order to have a base that enabled to recover the dialectical and complex character of the expression of the subject in the production of subjective sense. Methodologically we appealed to Qualitative Epistemology based on the dialogical, constructive-interpretative and unique character in the production of knowledge. We worked with a multiple case study, through observation of teaching practice, document analysis and used oral inducers to obtain expressions of the participants. In this paper the discussion is guided by the empirical movement of a teacher in searching conditions to promote the inclusion of students from special classes into regular schooling. It concluded that students with intellectual disabilities produce subjective senses about their school learning and can mobilize it or limit it, depending on the symbolic and emotional production process.
\end{abstract}

Keywords: Intellectual disabilities; Subject; Inclusion; Learning; Subjectivity.

\section{Introdução}

O processo de inclusão dos estudantes com diagnóstico de deficiência intelectual no ensino regular é prejudicado cotidianamente pelo náo reconhecimento da singularidade dos sujeitos, decorrente de um processo histórico de constituição social da função escolar, que ainda trabalha na perspectiva do nivelamento das aprendizagens. Mesmo no contexto das instituiçôes que têm caráter inclusivo, identifica-se que estas continuam, muitas vezes, priorizando somente a aquisição da aprendizagem de conteúdos curriculares e reconhecendo somente os eventos educacionais do contexto escolar como passíveis de promoverem a aprendizagem. O objetivo desse artigo é refletir sobre a singularidade dos estudantes com deficiência intelectual frente ao modelo homogeneizado da escola de conceber os processos de aprendizagem e, para isso, tomou-se como base empírica a trajetória de percepçóes singulares de quatro estudantes com diagnóstico de deficiência intelectual e uma professora de Classe Especial.

Inicialmente, vamos discutir dois conceitos que possibilitam evidenciar nuances do processo histórico da abertura da escola para estudantes com deficiência: a perspectiva da integração e a perspectiva da inclusão. Segundo Sassaki (1997), no modelo integrativo, a sociedade permanece imóvel e as pessoas com necessidades educativas especiais precisam adequar-se para lidar com os diferentes tipos de organização dentro de seu grupo social. Para lidar com sistemas de serviços especiais e 
tradicionais que compóem os sistemas educacionais, essas pessoas precisam moldar-se ao institucionalmente estabelecido.

O modelo de integração na educação impóe ao estudante o movimento de adaptar-se às demandas da escola da forma como se institucionalizou historicamente e vem enfatizando, quase que exclusivamente, o aspecto cognitivo-instrumental nos processos de aprendizagem dos estudantes. Há nesse modelo - cognitivo-instrumental - um tecido simbólico constituído pelas representaçóes sociais, pelas crenças e discursos que constituem o paradigma dominante na educaçáo.

O objetivo essencial desse modelo educacional vigente não aparece de forma explícita numa definição particular, mas caracteriza-se no dia a dia da prática escolar, no qual se integra o individualismo, a passividade e o reducionismo cognitivo-instrumental associado ao ensino, dando prioridade à assimilação em detrimento da produção própria do aluno e apoiando-se numa diversidade de paradigmas que tem sido dominantes nas ciências sociais ocidentais: racionalismo, cognitivismo, positivismo e essencialismo. (GONZÁLEZ REY, 2011, p. 48).

O movimento de integração dos estudantes com deficiência nas escolas regulares ganha forma, no Brasil, com as açóes preconizadas pela Lei n. 7.853/1989 (BRASIL, 1989) assegurando às pessoas com deficiência o pleno exercício de seus direitos básicos, como previsto no Art. $2^{\circ}$ : "a) a inclusão, no sistema educacional, da Educação Especial como modalidade educativa que abranja a educação precoce, a pré-escolar, as de $1^{\circ}$ e $2^{\circ}$ graus, a supletiva, a habilitação e reabilitação profissionais, com currículos, etapas e exigências de diplomação próprios". Mais adiante encontramos: "f) a matrícula compulsória em cursos regulares de estabelecimentos públicos e particulares de pessoas portadoras de deficiência capazes de se integrarem no sistema regular de ensino". Essa lei foi regulamentada dez anos depois pelo Decreto 3.298/1999 ao instituir a Política Nacional para a Integração da Pessoa Portadora de Deficiência, evidenciando que as tentativas de rompimento com o modelo de escola historicamente constituído ainda são recentes em nossa sociedade.

Integração é uma ação muito limitada, diante das ações requeridas pelos processos de inclusão. Integrar pressupóe colocar junto e depende do estudante sua adaptação ao que o sistema escolar oferece - sala especial, sala regular, sala de recursos. A inclusão é um princípio amplo e pressupóe que todos devam ter acesso à escola e esta é quem deve se adaptar, fazendo as adequaçôes necessárias para atender as particularidades dos processos de ensino e aprendizagem dos estudantes (MANTOAN, 1998).

Mantoan (1997, p. 11) esclarece que, "na inclusão, o vocábulo integração é abandonado, uma vez que o objetivo é incluir um aluno ou um grupo de alunos que já foram anteriormente excluídos”. O conceito de inclusão é resultado dos avanços que as discussôes sociais e acadêmicas consolidam nos últimos anos, de pensar uma educação para todos. Historicamente, podemos identificar movimentos que marcaram a abertura das discussôes como a Conferência Mundial sobre a Educação para Todos, ocorrida em 1990, e a Conferência Mundial sobre Necessidades Educativas 
Especiais, ocorrida em 1994. No princípio dos documentos gerados, em ambos os eventos em que o Brasil foi signatário, está o reconhecimento de que ainda existem muitas desigualdades na forma como a ação pedagógica é desenvolvida com nossas crianças e adolescentes. Nessa direção, também é conteúdo dos documentos a necessidade de que haja açóes que possam ir ao encontro dessas desigualdades, não para tornar todos iguais, mas para oferecer atenção diferenciada para necessidades diferenciadas. No Brasil, destaca-se o II Congresso Brasileiro e I Encontro Latino-Americano sobre Síndrome de Down, em 1997, e o III Congresso Ibero-Americano de Educação Especial, ocorrido em 1998 como marcos iniciais de discussão sobre os processos de inclusão, além da consolidação da Política Nacional de Educação Especial na Perspectiva da Educação Inclusiva em 2008.

As discussões sobre a inclusão sempre produzem reaçôes diversas, pois sua adesão na sociedade não é uma unanimidade. A inclusão é um processo complexo e historicamente recente em nossa cultura e carece de mudanças culturais e estruturais para que a compreensão de que todos têm direito à educação ganhe corpo social. Compreender que no conceito de 'todos', também estão incluídas as minorias sociais, independentemente de sua condição de gênero, classe, etnia, cor, condição física ou intelectual, requer ampliar a compreensão do papel educacional da escola como um agente social de desenvolvimento na e da sociedade (MITTLER, 2003; OMOTE, 2004).

Trata-se de uma mudança de paradigma educacional: o modelo de escola que nasceu para atender as elites sociais é desafiado a incluir todos em seus processos pedagógicos. Para Mantoan (2006, p. 16), "Se o que pretendemos é que a escola seja inclusiva, é urgente que seus planos se redefinam para uma educação voltada para a cidadania global, plena, livre de preconceitos, que reconheça e valorize as diferenças".

Incluir ultrapassa o princípio da igualdade dos direitos e requer uma educação fundada pelos princípios da equidade, ou seja, uma educação capaz de trabalhar de forma diferente com quem tem necessidades singulares. Incluir pressupóe desenvolver um trabalho diferenciado para estudantes que apresentem necessidades que são diferenciadas, sem segregá-los e sem gerar uma exclusão dentro da inclusão. A inclusão não almeja tornar todos iguais, mas almeja que todos encontrem espaços de aprendizagem e desenvolvimento consonantes com suas necessidades. Sem dúvida, a inclusão movimenta não só a escola, como instituição, mas, principalmente, os professores que se veem frente ao desafio da diversidade. Mittler (2003) destaca que é importante, nesse processo, que os professores sejam apoiados e valorizados em seu esforço, pois a inclusão exige mudanças de valores e crenças, que podem ser alcançadas diante de oportunidades de reflexão sobre esses processos de mudanças. $\mathrm{Na}$ prática, necessitam que suas ansiedades e necessidades sejam reconhecidas e apoiadas.

Transformar a escola em um espaço inclusivo não é simplesmente permitir que estudantes com perfis diferenciados convivam. É necessário que sejam compreendidos a partir da subjetividade constituída na multiplicidade histórica das quais também são seus próprios agentes. Faz-se necessário afastar, mais rapidamente possível, a convicção que está instituída na escola de que o estudante com deficiência 
intelectual é somente aquele descrito nos relatórios médicos e psicológicos, olhando para a história desse sujeito, como veremos nos casos apresentados.

Neste contexto, as práticas estabelecidas nas escolas e classes especiais que atendem estudantes com diagnóstico de deficiência intelectual ainda assumem, muitas vezes, caráter restritivo e desvinculado da construção histórica deles. Não há a devida compreensão sobre quem é esse estudante e o diagnóstico emitido pelos profissionais sobrepóe qualquer aposta de reconhecimento de expressão do sujeito, produzindo uma marca, um rótulo que pode reforçar ainda mais a deficiência. A pessoa com esse rótulo vai tornando-se invisível, não lhe sendo permitido falar de si e por si. Essas crenças, discursos, valores e representaçóes constituem a subjetividade social de escolas que têm, como já destacamos, as funçóes cognitivas-instrumentais no centro do processo educativo.

Há um entendimento generalizado que expressa que o melhor será o mais erudito. Observa-se que os estudantes com diagnóstico de deficiência intelectual são destituídos de suas singularidades, conforme afirma Arantes (2006, p. 32). "As instituições escolares, ao reproduzirem constantemente o modelo tradicional, não têm demonstrado condiçóes de responder ao desafio da inclusão social e do acolhimento às diferenças nem promover aprendizagens necessárias à vida em sociedade, particularmente a sociedades complexas do século XXI".

Essas instituiçóes, ao criarem categorias para organizar seus sistemas, geraram distorçôes que desconsideram os sujeitos envolvidos na dinâmica constituída, ou seja, desconsideram que a aprendizagem escolar é uma função do sujeito (GONZÁLEZ REY, 2003). Neste contexto, torna-se necessário aproximar o olhar sobre o ensino especial resguardando o caráter de promoção da aprendizagem com ênfase nas produçôes desse sujeito concreto, real. Há que se destacar que o papel atribuído à medicina tem forte predomínio sobre o educacional, torna o homem um ser genérico que é excluído quando se afasta do padrão de funcionamento que a sociedade capitalista instituiu, num contexto histórico, para responder a sua demanda produtiva. Como destacado por Vygotsky (2001), a escola não reconhece a natureza diferenciada dos processos de desenvolvimento e aprendizagem dos estudantes com deficiência e partem sempre do ponto de vista do desenvolvimento intelectual geral da criança. A escola tradicionalmente trabalha na perspectiva da uniformização da aprendizagem para conceber a inclusão no ensino regular, ou seja, seria passível de inclusão o estudante que tiver condiçóes de se aproximar da média de aprendizagem escolar, desrespeitando sua individualidade e, principalmente, seu processo de desenvolvimento.

$\mathrm{O}$ atendimento educacional especializado aos alunos com necessidades especiais, como está constituído, acaba por segregar e instituir o lugar onde o patológico é atendido. Se partimos do princípio de que todos devem conviver somente com seus pares - pessoas com deficiência - reforçamos a crença que nem todos são capazes de se desenvolver por meio da aprendizagem. A ordem instituída revela uma postura egoísta em relação ao outro, avaliando como menos humana a pessoa com deficiência. "Os instrumentos, as técnicas, os signos e os símbolos são desenvolvidos por e para esse tipo comum de pessoa, que frequenta espaços sociais, tem acesso às ferra- 
mentas de apropriação da cultura, estuda, cursa a educação básica, o ensino superior" (RAAD \& TUNES, 2011, p. 31).

A partir do exposto, podemos retomar o objetivo desse artigo, no qual discute-se o aprisionamento de estudantes com deficiência intelectual em classes especiais, diante de um modelo de escola que ainda caminha pautado pela homogeneização dos processos de ensinar e aprender. Se por um lado as escolas garantem o acesso de estudantes com diagnóstico, por outro ainda demonstram indícios de trabalharem em uma perspectiva de integração. Observa-se que, aos estudantes, náo estariam sendo oportunizadas situaçóes de aprendizagem que os possibilitem mobilizar recursos próprios para lidar com as questôes que fazem parte do processo de aprendizagem.

\section{Contextualização metodológica}

A pesquisa foi orientada pelos pressupostos da Epistemologia Qualitativa de González Rey $(2002,2005,2014)$ que argumenta em favor das relaçóes dialógicas entre o pesquisador e participantes, ressalta a importância da singularidade dos processos de investigaçáo e, principalmente, concebe a produçáo do conhecimento num processo construtivo-interpretativo. A construção está pautada pela possibilidade de gerar informaçóes no contexto da pesquisa, por ser resultado das reflexóes dos participantes, mobilizadas pelo pesquisador. Essas informaçóes, alinhadas com dados objetivos de pesquisa, produzem o conteúdo que será interpretado recursivamente pelo pesquisador, tendo como suporte sua base teórica. A interpretação é sempre a produçấo dinâmica de novos significados sobre as hipóteses temporárias que vão se modificando e adquirindo outros significados na tessitura produzida pelo pesquisador. O processo construtivo-interpretativo extrapola a ideia de coleta de dados, pois o pesquisador, na sua relação dialógica com os participantes, mobiliza reflexóes sobre temas que, muitas vezes, não faziam parte do repertório dos mesmos até aquele momento.

A pesquisa foi desenvolvida como estudo de caso, numa abordagem qualitativa, em uma classe especial que atende estudantes do ensino fundamental com deficiência intelectual. Participaram da pesquisa a professora da turma, quatro estudantes e os pais dos mesmos, por meio de entrevistas náo estruturadas, com o objetivo de produzir informaçôes sobre a condição dos estudantes no contexto da escola e sobre a deficiência.

Como recursos adicionais para produçáo das informaçóes, foram analisados documentos, laudos e relatórios individuais de aprendizagem, disponíveis nos dossiês dos estudantes, com objetivo de identificar o conteúdo dos mesmos e como esse conteúdo foi desenhando o percurso na escola. Posteriormente, também houve a participação das pesquisadoras, na condição de observadoras, nos momentos de avaliaçáo do desempenho dos estudantes entre a professora a equipe pedagógica da escola, visando os encaminhamentos para o ensino regular. A observação em sala possibilitou reflexốes sobre a expressão do estudante com deficiência intelectual na condição de sujeito na aprendizagem escolar. 
A partir da construção das informações sobre o processo de inclusão dos quatro estudantes, analisou-se a produção subjetiva construída pelos mesmos nas práticas escolares, tendo como pressupostos o aporte teórico desenvolvido por González Rey $(2005 ; 2011)$ que argumenta que o sujeito se constitui no confronto entre a subjetividade social e a subjetividade individual, em espaços socais e culturais, construídos historicamente. No processo de análise, a partir das informaçóes produzidas no decorrer da pesquisa, foram produzidos indicadores que, em confronto com outros indicadores gerados pelo conjunto da análise, constituíram o conteúdo apresentado a seguir.

\section{Os múltiplos casos em análise}

Os casos apresentados a seguir revelam que o foco da escola regular ainda encontra-se pautado por critérios generalizantes quando se trata da aprendizagem e de sua avaliaçáo, desvalorizando as pequenas conquistas individuais, ignorando os processos singulares vividos e alcançados por estudantes que apresentam deficiência intelectual. Observa-se que ainda há um processo de ranqueamento das aprendizagens e, com base na seleçáo de um rol de conhecimentos, a escola se organiza para promover a aprendizagem desconsiderando outros aspectos, como as emocionalidades, que estão na base dos sentidos subjetivos produzidos nas situaçóes de aprendizagem escolar ou não-escolar.

Neste contexto, quatro histórias de estudantes subsidiam a discussão. São histórias de estudantes que tiveram seus processos de inclusão protelados em muitos anos por que náo apresentavam os pré-requisitos exigidos na escola para a aprendizagem de leitura, escrita e matemática. Os relatos demonstram diversas manifestaçóes da expressão dos sujeitos vivos nesses estudantes, silenciados pela condição escolar que estấo inseridos.

\section{Caso 1: Janaína ${ }^{1}$ e o reencontro com a escola}

Janaína foi matriculada na classe de ensino especial após um afastamento de 7 anos da escola. Logo de início, a relação com a professora foi muito boa, houve uma empatia mútua. A professora questionava o motivo de ela estar na classe de ensino especial uma vez que destoava do perfil de comprometimento acadêmico. O perfil descrito era incompatível com aquela garota que a professora visualizava e convivia cotidianamente. A estudante apresentava fala articulada, autonomia na vida cotidiana com responsabilidade de ser cuidadora da máe idosa e da sua residência, locomovia-se com independência no trajeto até a escola fazendo uso de ônibus, manipulava dinheiro com conhecimento do valor real e social desse instrumento. Questionada sobre os motivos que a levaram a ficar afastada por tanto tempo da escola, relatou que náo gostava do ambiente escolar, que todos a achavam encrenqueira e que gostava de confusáo. Ainda no primeiro semestre a professora solicitou sua mudança para o ensino regular diante da constatação de que não apresentava dificuldades que justificassem sua permanência numa classe de ensino especial para estudantes com déficit intelectual.

A professora acreditava que aquele espaço poderia reforçar a aversão já apresentada pela escola anteriormente, porém muitos foram os entraves para a mudança 
e a estudante acabou permanecendo durante todo o ano. Com intervençôes pedagógicas para que construísse suas estratégias de aprendizagem, demonstrou dominar os conteúdos dados para o ingresso no $6^{\circ}$ ano. Assim, houve o processo de inclusão no $6^{\circ}$ ano e nas primeiras avaliaçóes pela equipe da sala de recurso, relatou-se que não haveria necessidade de adequaçáo curricular, pois a mesma acompanhava a turma com o desempenho esperado. Esse relato se confirmou em reunião pedagógica com os professores dos conteúdos curriculares com afirmativas de que a mesma apresentava desempenho, por vezes, superior aos seus pares de turma, colocando em dúvida o diagnóstico de deficiência intelectual.

Neste quadro fica explícito que durante toda a vida acadêmica não houve o reconhecimento da sua subjetividade individual, causando o afastamento da escola. "O reconhecimento da personalidade nos processos de aprendizagem e desenvolvimento estaria relacionado às possibilidades de compensação de cada sujeito, regidas pelas consequências sociais e pela realização psicossocial deste" (ROSSATO \& MITJÁNS MARTÍNEZ, 2011, p. 75).

Revendo a história da estudante, identificou-se que a mesma foi entregue pela mãe biológica em adoção, tendo seu diagnóstico médico fechado neste contexto. Naquele período, final da década de 1980, pouco se falava de inclusão e as pessoas com diagnóstico de déficit intelectual eram encaminhadas para os centros de ensino especial.

Os elementos constituintes da subjetividade social do Centro de Ensino Especial, não favoreceram uma relação de aprendizagem para a estudante, pois, quando passou por aquele espaço, lá encontravam-se todos os perfis de atendimento especializado: desde o estudante com múltiplas deficiências, com comprometimento na sua comunicaçáo, até estudantes com graus mínimos de dificuldade de aprendizagem, que estavam ali por apresentarem diagnóstico médico.

O percurso de Janaína ilustra como a produção subjetiva, associada ao diagnóstico de deficiência, com marcas da história social e cultural, pode produzir sentidos subjetivos que náo favorecem a aprendizagem. A postura de rejeiçáo à escola, que aparecia expressa nos documentos da estudante, está diretamente associada ao fato de que este ambiente lhe remete emocionalmente às situaçóes desconfortáveis e que criaram configuraçóes geradoras de danos relativas à forma como simbolizou sua relação com essa escola. Nesse contexto, a natureza dos sentidos subjetivos tornou-se desfavorecedora do processo de produção do conhecimento e de aprendizagem da estudante.

Caso 2: Weliton e a auto responsabilizaçáo pelo processo de mudança.

O estudante Weliton permaneceu por 11 anos no ensino especial, transitou entre as classes de ensino especial de algumas escolas e o centro de ensino especial. Os relatórios de aprendizagem indicavam que era alfabetizado, mas com comprometimento da fala, o que levava a troca de fonemas. Apresentava, ainda, dificuldade em atividades que envolviam raciocínio lógico-matemático. Nos contatos com a professora, demonstrava um perfil que não estava registrado nos relatórios: levava vida cotidiana com independência, com experiência de trabalhos e uma vida social intensa 
por conta de sua simpatia e comunicação; relatava as ocorrências vividas, inclusive através da escrita, com poucos erros ortográficos; seus ganhos pedagógicos poderiam ser dinamizados, pois participava de atividades de Educação Física com estudantes do ensino regular e circulava muito bem nesse meio.

As primeiras conversas no sentido de transferí-lo para o ensino regular foram animadoras, sua postura responsável foi potencializada, porém as conversas com a máe preocupavam a professora, pois ela resistia à ideia de vê-lo no ensino regular. Relatava que seu filho tinha muita dificuldade em matemática e que poderia ser frustrante, caso não conseguisse acompanhar a turma. A mãe construiu a ideia, a partir dos discursos das autoridades educacionais, que o seu filho era desprovido da capacidade de elaboração intelectual para a vida escolar, mas Weliton, ao afirmar-se positivamente com a mudança, constituía-se sujeito desse processo. Ele compreendia o significado da mudança e a influência positiva que ela geraria na sua vida.

No contexto da escola, a transferência foi conduzida ouvindo a mãe e o filho. Ele estava radiante com a mudança. Dois anos se passaram e ao encontrar com a mãe, ela relata seu arrependimento de ter resistido tanto tempo à inclusáo do filho. Segundo seu depoimento ele não teve dificuldade em adaptar-se, acompanha os conteúdos acadêmicos, com suporte da sala de recursos e, finalmente, encontra-se muito feliz. Visita a classe especial com frequência, pois permanece na mesma escola e mostra que já foi estudante destaque pelo desempenho apresentado em algumas disciplinas, inclusive em matemática.

Caso 3: Lucas e a conquista da independência

O estudante Lucas foi encaminhado ao centro de ensino especial no ano de 2008 com diagnóstico de Transtorno Global de Desenvolvimento, onde havia trabalhado com uma professora que o via com grande potencial de crescimento. A família, representada pela máe, acreditava no potencial de aprendizagem, lutava por atendimentos educacionais inclusivos para o filho, acompanhava as atividades escolares com suporte necessário em tudo que a professora solicitava. Os ganhos acadêmicos do estudante eram evidentes, pois possuía memória privilegiada para informaçóes. Aprendia dentro do padráo esperado para a faixa etária.

Ao ser encaminhado para a inclusão esbarrou-se na dificuldade de encontrar uma classe de integração inversa ${ }^{2}$ de $4^{\circ}$ ano para atender suas particularidades. A escola, depois de muitas negociaçóes, conseguiu abrir uma turma e a transferência de modalidade foi efetivada. Em conversa recente, a mãe relatou que Lucas ganhou mais independência, vai e volta sozinho de escola, coisas que ele desejava muito.

Caso 4: Ana e o desejo de não pertencer

Com 17 anos de idade, frequenta o ensino especial há 6 anos, sempre reconhecida pela dificuldade de avançar no processo de aquisição da leitura e escrita. Esse quadro a manteve na classe de ensino especial inibindo seu posicionamento diante da aprendizagem, pois, naquele espaço, estava distante da interação com os pares que poderiam mobilizar recursos subjetivos que a ajudariam na produçáo da aprendiza- 
gem. González Rey, ao abordar a importância do outro no desenvolvimento humano, questiona: "Qual é a posição que facilita ao outro sentir-se parte de um espaço social? Penso que é essa pergunta que deve nortear a educação inclusiva, porque sem essa condiçãoo subjetiva, a inclusão é irrealizável” (GONZÁLEZ REY, 2011 p. 59).

Neste contexto a iatrogênese tem nessa estudante sua produção mais bem sucedida, ou seja, criou um deficiente que é vítima de sistema escolar e que tem no relatório médico um referencial maior do que a representação do indivíduo presente na relação escolar. A constituição de sujeito social nunca foi levada em consideração na história escolar dessa estudante, pois foi obrigada a migrar do ensino regular para o especial, por não reter conteúdo.

Desde o início do trabalho com Ana, a professora se sentia próxima da estudante por conhecer sua história escolar e familiar. Sabia que tinha uma irmã ${ }^{3}$, que usava estratégias variadas para sobreviver à escola e que sua mãe, apesar de muito presente na vida escolar de ambas, não podia ajudá-las nas tarefas acadêmicas por não ser alfabetizada. Ana era residente em um setor de chácara próximo a escola, de difícil acesso, segundo relato da mãe, de onde só saia para ir às atividades escolares. Havia uma situaçáo de isolamento físico e quando não estava na escola permanecia em contato somente com a irmã e a mãe.

Neste contexto, manifestava dificuldade em falar com pessoas fora de seu círculo de convivência, nunca pegou um ônibus, metrô ou outro meio de transporte sozinha e havia relato que a própria máe perdeu-se em trajetos fora do circuito casa-trabalho. O perfil acadêmico da estudante sempre foi motivo de inquietude. Os relatos descreviam sua limitação em fixar conteúdos estudados, porém a professora a via com grande capacidade de articular estratégias para responder as situaçóes do cotidiano. $\mathrm{Na}$ área acadêmica, a estudante demonstrava dificuldade em aprender os signos relativos aos algarismos, mas refazia a sequência oralmente dirigindo-se ao calendário fixado na parede da sala e encontrava o registro gráfico que procurava. As estratégias usadas por ela passaram a surpreender cada vez mais a professora que identificava a limitação de memorização dos conteúdos escolares, porém, reconhecia a produção intelectual realizada para responder as questóes propostas cotidianamente.

Os dois perfis estavam presentes nos relatórios de aprendizagem individual do ano de 2010: "a estudante apresenta dificuldade para desenvolver as atividades propostas, pois não consegue fixar o conteúdo estudado e cada dia é como se fosse um recomeço para ela". Porém, em outro momento, o tom do relato era outro: "a estudante se destaca nas aulas de educaçáo física e consegue acompanhar as estudantes da sétima série, nos jogos amistosos. Ela gosta de participar das rodas de notícias, onde lemos jornal e participa ativamente das aulas de ciências, história, geografia e laboratório de informática”. O relatório finaliza indicando que a estudante não conseguiu vencer os conteúdos propostos para ela no ano, portanto ela deverá permanecer em classe especial no ano de 2011, para o seu processo de letramento.

$\mathrm{Na}$ análise deste documento percebe-se como a limitação é o foco do processo escolar e não a estudante. Ela era descrita dentro do padrão estabelecido pelos pares 
da mesma idade, mas com perfil acadêmico de que dificilmente conseguirá vencer os conteúdos.

As conversas preliminares estabelecidas com Ana sobre a necessidade de caminhar em seu processo de escolarização e acompanhar sua irmã, no ensino regular, fez com que assumisse uma postura afirmativa, arriscando a revelar-se. Gradativamente iniciou a realização das atividades propostas de leitura, conseguindo fazer avanços que eram considerados significativos para ela. No primeiro momento a professora estabeleceu um diálogo com a estudante objetivando compreender qual sua opiniáo sobre uma possível mudança para o ensino regular. A simples pergunta, aparentemente, gerou a possibilidade de produção de novas aprendizagens, uma vez que já havia acenado várias vezes que não gostava do lugar onde estava. A perspectiva de sair dele, onde avaliava que era identificada pelos demais membros da escola como deficiente, aparentemente produziu mudança de sentidos subjetivos em relação a aprendizagem.

Para propiciar situaçôes informais de aprendizagem, objetivando a meta de incluí-la no ensino regular, a professora foi realizando algumas saídas do ambiente escolar com visita ao shopping, zoológico e ao cinema, pois observou que haviam poucos momentos de contatos sociais na vida de Ana, com limitação de convivência às pessoas e espaços da casa e da escola. Nas ocasióes de passeios a estudante mantinha-se distante dos demais integrantes da turma, demonstrando que não quereria vincular sua imagem ao ensino especial, nem mesmo permitia uma foto em conjunto, apesar de não expressar qualquer hostilidade em relação aos colegas.

Considerando que a estudante começava fazer uso da linguagem escrita foram introduzidos dois meios de produção de informação, presentes em sua vida cotidiana: telefone celular e a rede social Facebook. A intençáo da professora era mostrar como usar ferramentas para aproximar o diálogo e dar uma funcionalidade à produção escrita, uma vez que conseguia fazer os registros sob a supervisão da professora, no espaço de sala de aula, mas observava-se que não considerava essa ação como algo relevante. O diagnóstico de deficiência intelectual da estudante é controverso, com aceno na direção de uma investigação de distúrbio da linguagem, com vários encaminhamentos para a avaliação por um fonoaudiólogo, porém sem realização pela família, que nunca conseguiu o atendimento por haver escassez desse profissional na rede pública tanto de educação como de saúde. Houve solicitação, também, de novas avaliaçôes pela equipe psicopedagógica sem qualquer avanço neste sentido. "No uso psicométrico dos testes de inteligência esqueceu-se a dimensão subjetiva presente em qualquer expressão do sujeito; portanto, não eram consideradas as emoçóes envolvidas na realizaçáo dos testes, assim como tampouco o efeito sobre o que pretendiam medir" (GONZALEZ REY, 2002 p. 54). Gradativamente ela foi construindo recursos para a leitura e escrita abrindo as portas para um futuro processo de inclusão, ainda sem consolidação durante a realização da pesquisa.

Os três primeiros casos - Janaína, Weliton e Lucas - são ilustrativos de situaçóes de estudantes que tinham diagnósticos que os mantiveram por muitos anos no ensino especial e que, quando lhes foi dado a possibilidade de mudar de modalidade, apresentaram ganhos acadêmicos e sociais consideráveis. A constituição da subjetividade individual se organiza nos contextos sociais de forma recíproca e permanente e 
a mudança lhes possibilitou outras produçóes subjetivas, reconfigurando a condição de sujeito.

No quarto caso relatado, a estudante foi impedida de avançar para situaçôes de aprendizagem que fizessem mais sentido para ela. Observa-se que, "as pessoas portadoras de necessidades educacionais especiais têm problemas intelectuais em decorrência de dificuldades no desenvolvimento de suas potencialidades como resultado do tipo de relaçôes e práticas que dominam a vida social" (ROSSATO \& MITJÁNS MARTÍNEZ, 2011, p.51). Ainda sobre o último caso, não podemos deixar de destacar as condiçôes de seu convívio social. Na vida de Ana, todo seu percurso de sujeito histórico foi desconsiderado e o diagnóstico de deficiência passou a representá-la. Não houve a devida leitura dos aspectos que nortearam o seu desenvolvimento e a sua subjetividade.

Os quatro casos apresentados são ilustrativos de como os estudantes com deficiência intelectual possuem recursos que lhes possibilitam expressarem-se como sujeitos em suas atividades cotidianas. A despeito da incapacidade imposta socialmente, quando encontram as oportunidades, revelam uma produçáo subjetiva capaz de mobilizar os processos de aprendizagem escolar. Resta, ainda, que todos os agentes educacionais tenham olhos para enxergar as possibilidades desses estudantes a despeito dos rótulos e diagnósticos deterministas que são corriqueiramente submetidos. "A proposta da escola inclusiva deve trabalhar essencialmente no resgate da cidadania e no desenvolvimento de espaços sociais que permitam o engajamento dos escolares com defeito em relação de simetria com seus colegas" (GONZÁLEZ REY, 2011, p. 52).

Neste contexto, observamos que o estudante com diagnóstico ainda é destituído socialmente de sua historicidade. Nos casos relatados houve, durante a história desses estudantes, a ênfase nos aspectos assimilativos e mecanicistas da aprendizagem e a produção simbólica emocional, que emergem na produção humana, não foi considerada. A escola, muitas vezes, ainda parece desconhecer o princípio de que as pessoas expressam afetos que se relacionam com os processos simbólicos, independente do diagnóstico associado a sua condição. $\mathrm{O}$ comprometimento em relação à aprendizagem aparecerá em funçẫo da fragilidade dos vínculos que estabelecem nos espaços de vida social a que pertencem. O diagnóstico, em si mesmo, é incapaz de expressar de antemáo as possibilidades do indivíduo.

\section{Considerações finais}

A proposta desse artigo foi lançar um olhar sobre a importância do processo de inclusão para estudantes que ficam impedidos do convívio com os pares, deixando de mobilizar importantes recursos psicológicos para a aprendizagem escolar. Essa barreira tem sido historicamente gerada pelo modelo homogeneizado da escola de conceber os processos de aprendizagem e de ensino e pelo reducionismo da aprendizagem ao processo cognitivo-instrumental. Incluir implica aceitar e efetivar a diversidade como paradigma social e educacional. 
Como mencionado no início do texto, há um aparato legal que sustenta a inclusão dos estudantes com diagnóstico de deficiência intelectual, entretanto faz-se ainda necessário mobilizar a comunidade escolar para reconhecer e trabalhar com as expressóes singulares desses estudantes. A expectativa deles terem que atingir certo perfil acadêmico, num contexto de segregação, é danosa e contraditória ao próprio processo de inclusão. Na prática, estaria sendo exigindo dos estudantes de classes especiais um perfil que está além do que a escola está oferecendo, reforçando a ideia, tão combatida, da culpabilização do estudante pelas suas dificuldades e limitaçôes, isentando a escola da responsabilidade pela aprendizagem e desenvolvimento de todos. A perspectiva de redimensionar o paradigma que está posto, em termos do modelo homogeneizador da escola, traz à tona desafios extremamente complexos que precisam ser enfrentados no cotidiano escolar.

Há de se reconhecer que os professores, principalmente das licenciaturas, sentem-se limitados na possibilidade de trabalho com estudantes que apresentam deficiência intelectual por terem recebido uma formação pautada em princípios de aprendizagem e desenvolvimento que são incoerentes com a inclusão e baseados predominantemente nos aspectos cognitivos da aprendizagem, ignorando as constituiçóes subjetivas dos estudantes e as particularidades dos processos de desenvolvimento. Os casos analisados evidenciam que a ação do outro, nesse caso da professora, foi determinante nos processos de inclusão por ter sido capaz de perceber a expressão de um sujeito ativo nesses estudantes e de mobilizar recursos para que se desenvolvessem com autonomia. A inclusão se faz por meio de açóes inclusivas de pessoas reais que vivem o cotidiano das escolas e que são sensíveis ao outro, reconhecendo-os como sujeitos em desenvolvimento. Destacamos, a seguir, algumas açôes que podem ser desenvolvidas no espaço escolar possibilitando que os estudantes com diagnóstico de deficiência intelectual encontrem meios de serem reconhecidos e valorizados em suas formas diferenciadas de aprender:

- Usar os espaços da coordenação pedagógica para traçar estratégias que visem potencializar a construção das aprendizagens dos estudantes. Isso pode ocorrer por meio de um maior entrosamento entre os professores das disciplinas e por meio de discussôes a respeito das estratégias de ensino. Essa discussão faz-se necessáriana constituiçáo dos espaços escolares e de estratégias metodológicas de ensino direcionadas a indivíduos singulares e subjetivamente constituídos;

- Elaborar os projetos pedagógicos da escola dentro de uma orientaçáo inclusiva, procurando traçar estratégias para que os sujeitos aprendam, mesmo que em ritmos e estilos diferenciados. Desde esse paradigma, os professores precisam perceber-se parte do processo de inclusão e a escola, e seus profissionais, necessitam organizar a dinâmica escolar para que o estudante participe ativamente de todas as atividades produzindo conhecimento, posicionando-se como um sujeito que aprende; 
- Como um espaço inclusivo, a escola pública precisa propiciar espaços de debates com a comunidade sobre o processo de inclusão, garantindo que esses estudantes sejam ouvidos em suas expectativas, desejos, frustraçôes. A inclusão é um processo social, não somente educacional, construído em uma dinâmica complexa e subjetiva que a escola está vivenciando;

- Divulgar as práticas significativas que são desenvolvidas na escola para que sirvam como parâmetros em outros espaços sociais, mostrando que é possível realizar ações pedagógicas que oportunizem a aprendizagem dos sujeitos;

Por fim, destacamos que a inclusão é um desafio a ser enfrentado por todos. A complexidade que envolve o processo de desenvolvimento e de aprendizagem deve ser discutida na formação de muitas carreiras profissionais, com destaque para a carreira dos professores. Essa discussão possibilitaria o processo de inclusão real em que os estudantes com diagnóstico de deficiência intelectual fossem percebidos como sujeitos com garantia de respeito a sua singularidade na escola e na sociedade.

\section{Referências}

ARANTES, V. A. Apresentação. In: MANTOAN, M. T. E. Igualdade e diferenças na escola: como andar no fio da navalha. São Paulo. Summus, 2006.

BRASIL. Lei no. 7.853, de 24 de outubro de 1989. Dispóe sobre o apoio às pessoas portadoras de deficiência, sua integração social, sobre a Coordenadoria Nacional para Integração da Pessoa Portadora de Deficiência, institui a tutela jurisdicional de interesses coletivos ou difusos dessas pessoas, disciplina a atuaçáo do Ministério Público, define crimes, e dá outras providências. Diário Oficial da União. 25 out. 1989.

GONZÁLEZ REY, F. Pesquisa qualitativa em psicologia: caminhos e desafios. São Paulo: Pioneira Thomson Learning, 2002. 2003.

. Sujeito e subjetividade: uma aproximação histórico-cultural. São Paulo: Pioneira Thomson Learning, 2005.

Subjetividade, complexidade e pesquisa em psicologia. São Paulo: Pioneira Thomson Learning,

Ideias e modelos teóricos na pesquisa construtivo-interpretativa. In: MARTÍNEZ, A. M.; NEUBERN, M.; MORI, V. D. (Orgs.). Subjetividade contemporânea: discussōes epistemológicas e metodológicas. Campinas, SP: Alínea, 2014.

Os aspectos subjetivos no desenvolvimento de crianças com necessidades especiais: além dos limites concretos do defeito. In: TACCA, M. C.; MARTÍNEZ, A. M. (Orgs.). Possibilidades de aprendizagem: açóes pedagógicas para estudantes com dificuldades e deficiências. Campinas: Alínea, 2011.

MANTOAN, M, T. E. Integração x Inclusão: Escola (de qualidade) para Todos. PÁTIO-Revista Pedagógica, 2 (5), maio/jul. 1998.

A integração de pessoas com deficiências: contribuição para uma reflexão sobre o tema. São Paulo: Memmon, 1997.

O direito de ser, sendo diferente, na escola. In: RODRIGUES, D. Inclusáo e Educaçáo: Doze Olhares sobre a Educação Inclusiva. São Paulo: Summus, 2006.

MITTLER, P. Educaçáo inclusiva: contextos sociais. Tradução: WindyzBrazão. Porto Alegre: Artmed, 2003.

OMOTE, S. (Org.). Inclusão: intenção e realidade. Marília: FUNDEPE, 2004.

RAAD, I. L. F. ; TUNES, E. Deficiência como iatrogênese. In: TACCA, M. C. ; MARTÍNEZ, A. M. (Orgs.). Possibilidades de aprendizagem: açōes pedagógicas para estudantes com dificuldades e deficiências. Campinas: Alínea, 2011. 
ROSSATO, M.; MARTÍNEZ, A. M. A superação das dificuldades de aprendizagem e as mudanças subjetivas. In: TACCA, M.C.; MITJÁNS MARTÍNEZ, A. (Orgs.). Possibilidades de aprendizagem: açóes pedagógicas para estudantes com dificuldades e deficiências. Campinas: Alínea, 2011.

SASSAKI, R. K. Inclusáo: construindo uma sociedade para todos. Rio de Janeiro: WVA, 1997

VYGOTSKY, L. S. Psicologia e pedagogia. São Paulo. Martins Fontes, 2001.

\section{Notas}

${ }^{1}$ Respeitando o sigilo e a identidade dos participantes, todos os nomes utilizados são fictícios.

${ }^{2}$ As classes de integração inversa organizam-se com reduçâo do número de estudante em relação às classes comuns, conforme preconizado no artigo $2^{\circ}$ do decreto $n^{\circ} 22.912 / 2002$ que dispóe sobre atendimentos especializados aos estudantes portadores de deficiência na Educaçáo Básica em estabelecimentos públicos e particulares no âmbito do Distrito Federal, regulamentando a Lei no 2.698/2001

${ }^{3}$ Sua irmă, no ensino regular, acompanhava a escrita por meio da cópia feita pela professora no quadro, juntavase a colegas que realizavam as atividades e através dessa estratégia mantinha em dia tudo que a professora expunha no quadro. Sua forma particular de agir a fez compreender o funcionamento da escola, copiando rapidamente os conteúdos, agregando-se a pares que respondiam as demandas da professora e assim foi se apropriando do repertório acadêmico necessário para avançar no processo de escolarização, sempre lutando contra a possibilidade de ter o mesmo destino de sua irmā.

\section{Correspondência}

Roseane Cunha - Colonia Agricolas Águas Claras, chácara 16a, lote 10, CEP: 71.090-165. Guará - Distrito Federal.

E-mail: roseane.p.cunha@bol.com.br - maristelarossato@gmail.com

Recebido em 26 de novembro de 2014

Aprovado em 04 de maio de 2015 